\title{
Development of an urban flood model for Bengaluru city, Karnataka, India
}

\author{
P. P. Mujumdar*, M. S. Mohan Kumar, G. S. Sreenivasa Reddy, Shubha Avinash, Ila Chawla, \\ G. S. Kaushika, Aisha Sharma, Saimy Davis, Tom Thomas, Claris Ann Thomas, \\ Vanishri S. Jahagirdar, H. M. Arpitha, K. Parashuram and Anjan Kumar
}

In the recent past, a steep increase in the frequency and intensity of flash floods in urban regions has resulted in significant damage to life and property, necessitating a holistic approach to address the problem. An integrated urban flood model for Bengaluru city, Karnataka, India has been developed with a modular approach, which includes real-time rainfall and weather monitoring, and a rainfall forecast system feeding into a comprehensive hydrologic flood model. An output management and information dissemination channel for timely disaster preparedness and response is integrated in the framework, with active involvement of the government. The framework and outcomes of the system are summarized and presented here.

Keywords: Disaster preparedness, flash floods, rainfall forecast, urban flood model, weather monitoring.

WITH a surge in urbanization in India over the last few decades, many moderately sized and populated cities are now turning into megacities. Bengaluru, Karnataka in particular, transformed from being the garden city to the Silicon Valley of India in a short span of about three decades, especially since the early $2000 \mathrm{~s}^{1}$. Increase in the developed areas in the city and the associated changes in the land surface properties have resulted in an increase in the overland flows, leading to severe flood events during the last decade. There has also been an increase in shortduration high-intensity precipitation events in the city that cause floods. Occurrence of such heavy flood events, year after year, causing huge disruption to normal life and resulting in significant economic loss, necessitates an integrated approach to address the urban flooding problem in a holistic manner.

An integrated urban flood model (UFM) for Bengaluru city is being developed by the Indian Institute of Science (IISc), Bengaluru, in collaboration with the Karnataka State Natural Disaster Monitoring Centre (KSNDMC), Bengaluru in a time-bound project, to mitigate the impacts of floods in the city. The other partners in this project are the Centre for Study of Science and Technology Policy (CSTEP), Spatika Information Technologies

P. P. Mujumdar, M. S. Mohan Kumar, Ila Chawla, G. S. Kaushika, Aisha Sharma, Saimy Davis, Tom Thomas, Claris Ann Thomas and Vanishri S Jahagirdar are in the Interdisciplinary Centre for Water Research (ICWaR), Indian Institute of Science, Bengaluru 560012 , India and G. S. Sreenivasa Reddy, Shubha Avinash, H. M. Arpitha, K. Parashuram and Anjan Kumar are in the Karnataka State Natural Disaster Monitoring Center (KSNDMC), Bengaluru 560 064, India.

*For correspondence. (e-mail: pradeep@iisc.ac.in) and Geokno along with Bruhat Bengaluru Mahanagara Palike (BBMP), Bangalore Development Authority (BDA) and Bangalore Water Supply and Sewerage Board (BWSSB) as the stakeholders. The framework of the UFM project is based on the outline from the Integrated Urban Flood Management for India (IUFM) project (20132016; https://sites.google.com/view/itraiufm), wherein the controlled watershed in the IISc campus along with other sub-catchments in Bengaluru city were considered as pilot study areas.

The present project aims at developing a comprehensive, near-real time flood forecast model for Bengaluru city. This involves the development of a precision forecast system using a high-resolution numerical weather prediction model setup exclusively for the city. To develop an efficient forecast system, a well-established network of water-level sensors, integrated two-dimensional flood model, which along with the water levels provides information on the spread of flood waters (vis-à-vis flood inundation), an automated information dissemination system for preparing and mitigating flood-related damages and to utilize flood water as a resource is proposed. One of the critical aspects for the development of the model is to collect data from various agencies, and use them appropriately for simulating floods in the city.

The UFM for Bengaluru city comprises six components, viz. (i) establishment of sensor and rain gauge network and data aggregation; (ii) precise rainfall forecast system; (iii) comprehensive flood modelling; (iv) flood information dissemination and feedback; (v) innovative technologies for flood mitigation and management; and (vi) documentation and packaging of flood management 


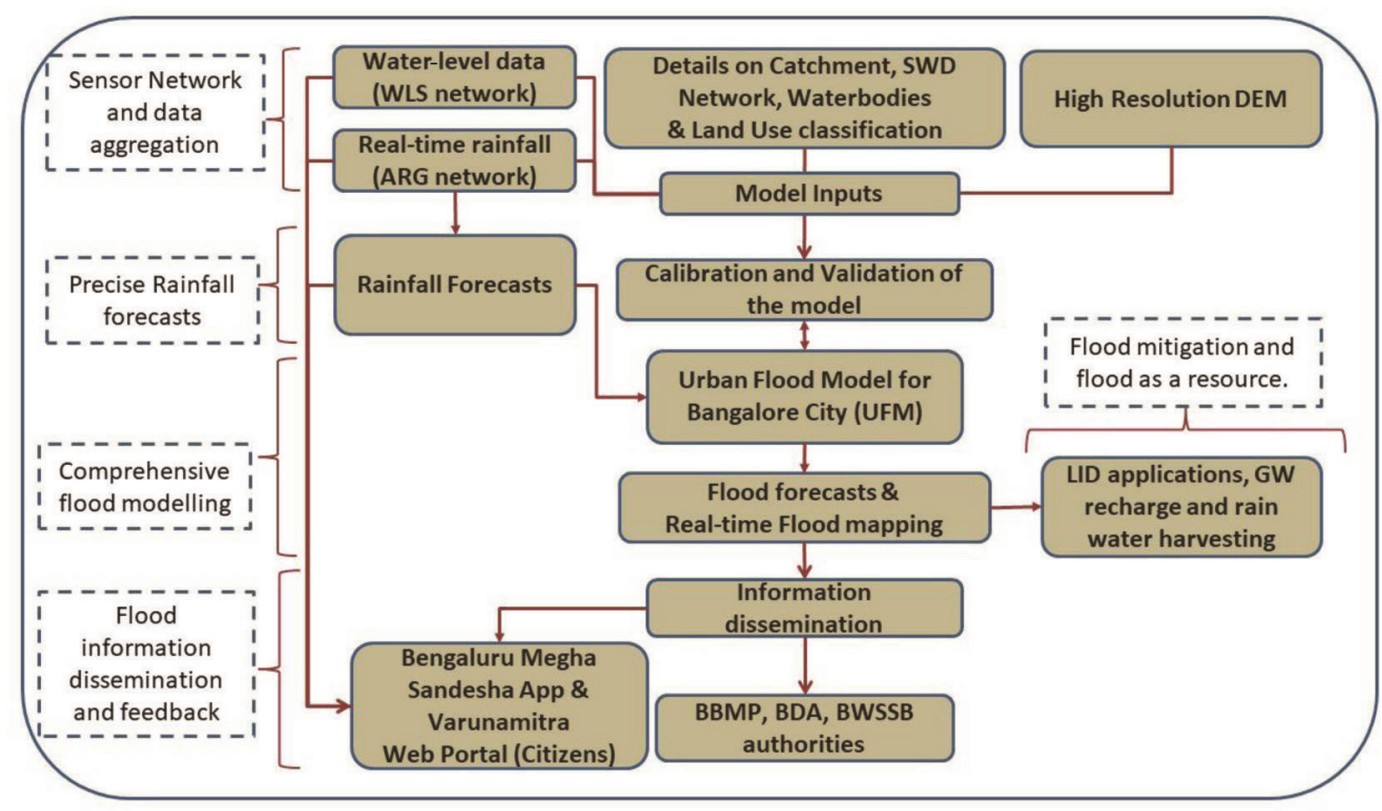

Figure 1. Framework of the urban flood model for Bengaluru city, Karnataka, India.

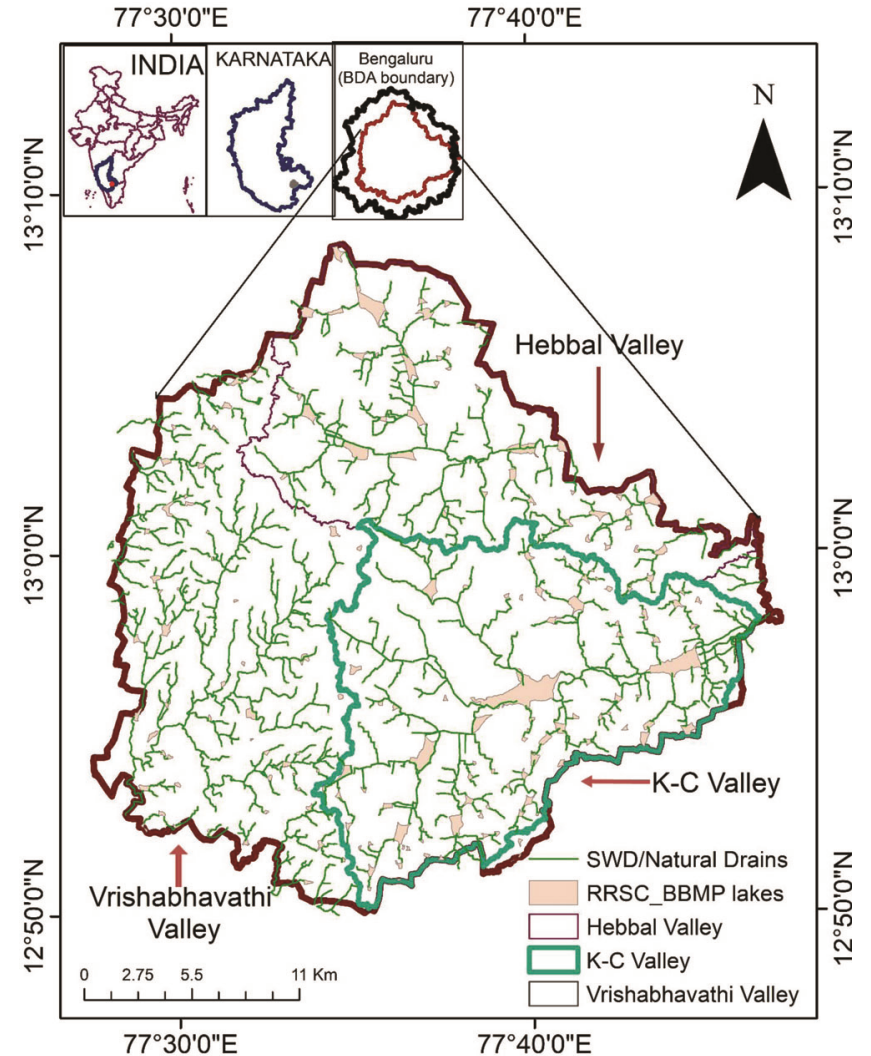

Figure 2. Location and major valleys in Bengaluru (BBMP area) with stormwater and natural drains and lakes (source: Hebbar et $a l^{2}$ ).

system. Figure 1 shows the framework of the project. The city of Bengaluru (urban) has an area of 709 sq. km, administered by BBMP within the BDA area of 1245 sq. $\mathrm{km}$ (ref. 1). It is located at an average elevation of about $900 \mathrm{~m}$ amsl. The natural terrain of the city has three major outward-draining valleys, viz. Hebbal Valley (draining from northwest to east), KoramangalaChallghatta $(\mathrm{KC})$ valley (draining from south to northeast) and Vrishabhavathi Valley (draining from north to south; Figure 2). The valleys include a number of lakes/storage tanks which are interconnected through natural streams. Rapid urbanization and encroachments have caused the lakes to shrink and have reduced their storage/infiltration capacity $^{2}$. Study of the land-use pattern indicates that about $30 \%$ of the central part of Bengaluru is impervious, which results in the generation of higher run-off as overland flow during an intense rainfall event ${ }^{1,3}$.

Bangalore region receives about $850 \mathrm{~mm}$ of average annual rainfall, of which about $80 \%$ is received during the southwest and northeast monsoon seasons. It is, however, important to note very high spatial variation of the extreme precipitation events. Figure 3 shows a spatial map of mean return levels $(\mathrm{mm})$ for a 10-year return period for annual maximum precipitation. It can be seen that the mean return levels on the western part of Bengaluru city are higher by $10 \%$ compared with the other parts for annual maxima ${ }^{4,5}$.

\section{Establishment of sensor and rain gauge network and data aggregation}

To monitor the flow during flood events, a network of 100 automatic rain gauges (ARGs) and 25 water-level sensors (WLS), across Bengaluru have been installed and are maintained by KSNDMC in collaboration with BBMP. The real-time rainfall data are obtained at a 
temporal resolution of $15 \mathrm{~min}$ from the ARGs through a Subscriber Identity Module (SIM) based communication system to the server at KSNDMC, with one rain gauge for every $7 \mathrm{sq}$. $\mathrm{km}$. The telemetric WLSs are set up on the storm water drains (SWDs) at various significant locations based on the identified flood-vulnerable areas, and accessibility to and safety of the sensors. The WLS transmit data at 15 min temporal resolution, which is critical during high flood events. The networks are equipped with alert systems to keep the authorities informed if the level crosses a threshold, helping them to prepare in case of flood events. Figure $4 a$ shows locations of the installed WLS and ARG network.

The flood modelling requires collection of fineresolution data for mapping the flow patterns. Contour map of $1 \mathrm{~m}$ spatial resolution provided by BDA has been processed to obtain the digital elevation model (DEM). Details regarding lakes and stream, watersheds, buildings, roads and railways were also obtained from BDA. The SWD network and the administrative boundaries were obtained from BBMP. The flood-vulnerable zones classified were obtained from BBMP and other governmental bodies through KSNDMC. Figure $4 b$ shows the SWD network and flood-vulnerable areas identified in Bengaluru city.

\section{Rainfall forecast}

The rainfall forecasts were obtained from Weather Research and Forecasting (WRF) model data available with the Space Applications Centre (SAC), Indian Space Research Organisation (ISRO), Ahmedabad. The forecasts were obtained for $12,24,36,48,60$ and $72 \mathrm{~h}$ daily at $12: 30 \mathrm{pm}$ for all the $100 \mathrm{ARG}$ locations with up to

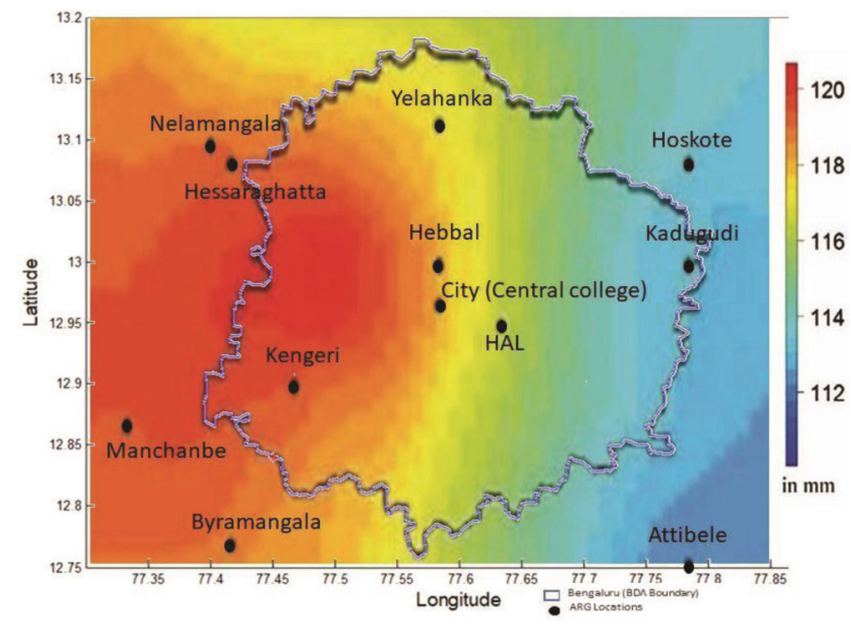

Figure 3. Spatial map of mean return levels $(\mathrm{mm})$ of annual maximum precipitation with a 10 -year return period for Bengaluru (BDA boundary) (Source: Rupa and Mujumdar ${ }^{5}$ ).
$5 \mathrm{~km}$ spatial resolution according to the requirements of KSNMDC. The real-time data from ARG sensors and automatic weather stations (AWS) were shared five times between 5 am-7 am daily with the SAC WRF model through ftp servers to capture the real-time, locationspecific weather conditions. This facilitates an increased accuracy in forecasts based on the observed data. In general, the SAC forecasts are seen to perform well for light-to-moderate rainfall range. A finer-resolution WRF model is being setup at IISc using boundary conditions given by the US National Centers for Environmental Prediction (NCEP) with a resolution of $25 \mathrm{~km}$, including two nests at 9 and $3 \mathrm{~km}$. The WRF model forecasts at $3 \mathrm{~km}$ resolution are now being tested with the observed rainfall data from the installed ARGs. This high-resolution WRF model will be integrated with the system in subsequent versions of the model.

\section{Comprehensive flood modelling}

The UFM flood model has been developed using the storm water management model (SWMM) of the United States Environmental Protection Agency (EPA). SWMM is a dynamic rainfall-run-off simulation model designed specifically for urban regions, and is used to compute the run-off generated from rainfall after accounting for various losses from the system. The input datasets required for the SWMM model set-up, viz. ARG locations and rainfall data, sub-catchments, SWD network (location and channel geometry), and impervious area in the form of buildings and roads, topographical data and DEM data (obtained from contour maps) were obtained from KSNDMC, BDA and BBMP. The nodes, drains, ARG locations and sub-catchments were pre-processed, connected and imported from ArcGIS to SWMM. Initial flow in the drains was assumed to be at $25 \%$ of the total capacity and maximum flow is the full capacity of the drains. The surface roughness coefficient (Manning's $n$ ) was assigned for concrete-lined SWDs as 0.015 , and for other surfaces based on the respective land-use types and the literature reports ${ }^{6}$. Lakes act as major sinks for the flood waters generated by run-off and the existing lakes are represented as point storage units in the model ${ }^{2}$. The precipitation input to the model was added from the installed rain gauge network. The simulated peak run-off, run-off volume and critical and flood-vulnerable locations were obtained using rainfall data of $15 \mathrm{~min}$ resolution generated during a historical extreme event as an input to the model. The flow was routed kinematically based on the continuity and momentum equations, which allow flow to vary spatially and temporally. The results were obtained in the form of hydrographs for each junction/ node in the model. The outcomes of the SWMM serve as inputs to the HEC-RAS model to obtain flood inundation maps. 

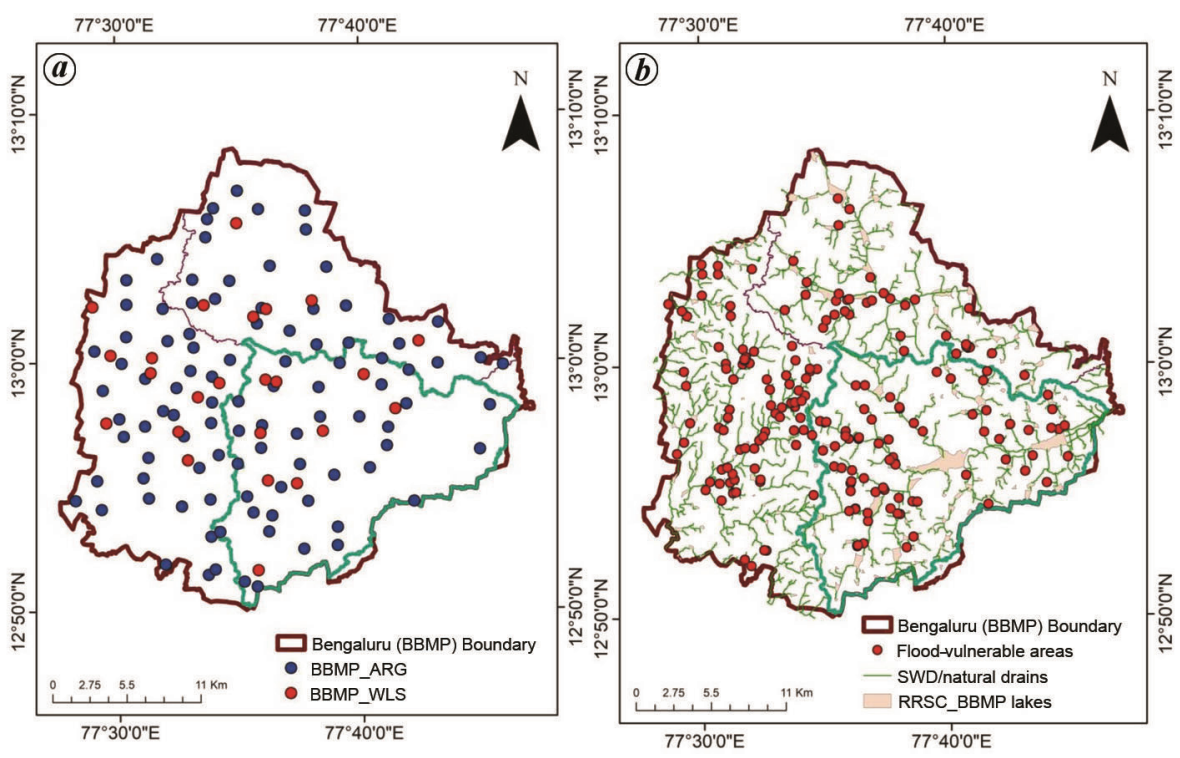

Figure 4. (a) Location of automatic rain gauges (ARGs) and water-level sensors (WLS) in Bengaluru city (BBMP area), and (b) SWD network (source: BBMP) and flood-vulnerable areas (source: KSNDMC).
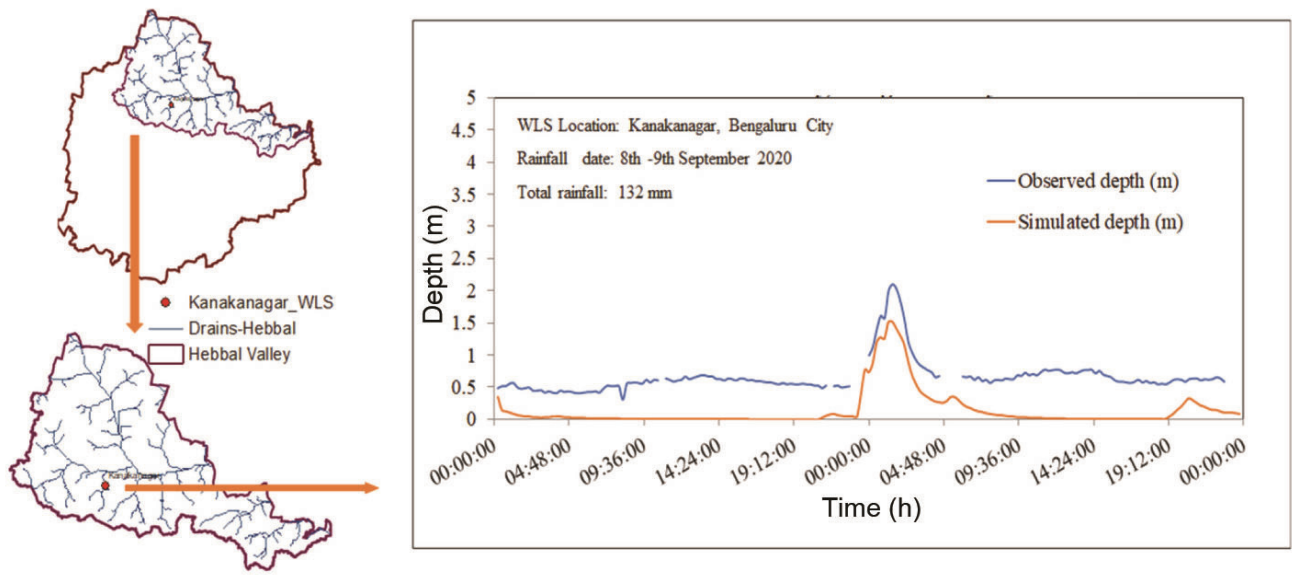

Figure 5. Comparison of observed and simulated water levels for a location in the Hebbal Valley, Bengaluru city.

\section{Model calibration and validation}

The model was calibrated by repetitive runs with verification based on the recorded water-level data from the WLS network for high flood events that occurred in 2016. Figure 5 shows a comparison of the observed (WLS) and simulated (SWMM model) water levels for a location in Hebbal Valley, for the event that occurred on 8-9 September 2020. The model was then run for two high flood events that occurred on 7-8 May 2019 and 25-26 June 2020.

The city witnessed widespread heavy rainfall on 7 and 8 May 2019. The Doddabidrekal ARG station recorded a cumulative rainfall of $150 \mathrm{~mm}$ in $24 \mathrm{~h}$, with an observed hourly maximum of $98 \mathrm{~mm}$. Similarly, a high-intensity rainfall event was observed in the Vrishabhavathi valley on the 25-26 of June 2020, with a recorded cumulative rainfall of $185 \mathrm{~mm}$ in $24 \mathrm{~h}$ with an hourly peak of $136 \mathrm{~mm}$. This latter cumulative peak was the highest recorded rainfall for Bengaluru since 1891. The model-simulated inundation depths at the flood vulnerable areas (Figure $4 b$ ) were validated with the recorded depths at the respective locations for these two events. Figure 6 shows the model outcomes (spread and depth of flood/ inundation) for $\mathrm{KC}$ and Vrishabhavathi valleys.

\section{Model outcomes: near real-time flood mapping and flood forecasting}

The near real-time flood inundation maps were prepared and despatched based on the outcome of the flood model 

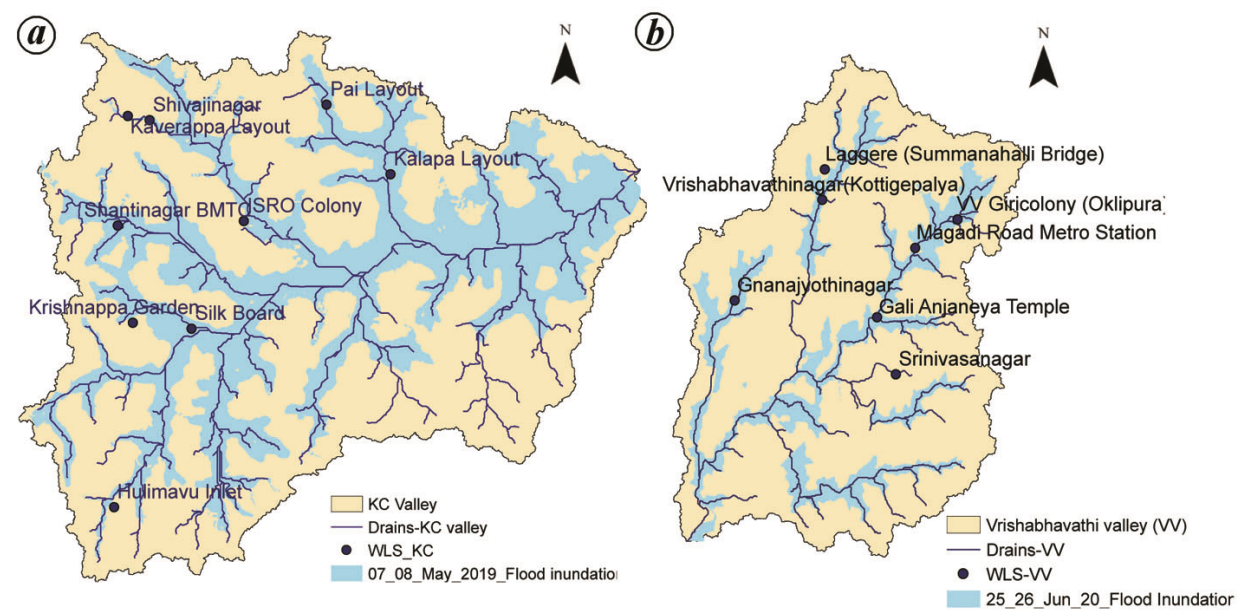

Figure 6. Flood inundation map of (a) KC Valley on 7 May 2019 and (b) Vrishabhavathi Valley on 25 June 2020.

with real-time observed rainfall from the ARGs as inputs, and were correlated with the WLS data for various locations. The rainfall forecasts, which are customized based on the observations from the AWS and ARGs for better accuracy were procured daily from SAC. The flood forecasts were obtained with a lead time of $12-72 \mathrm{~h}$, by executing the flood model for the forecasted rainfall data.

\section{Flood information dissemination and feedback}

The model outcomes and relevant information were disseminated as deliverables in three stages. (1) The rainfall and flood forecast warning system. (2) The post-flood damage alert system. (3) Bengaluru Megha Sandesha mobile application and Varunamitra dynamic web portal.

Based on the forecasted rainfall and outcomes of the flood model for the occurrence of a high rainfall event, the flood and rainfall forecast system provides relevant information for sending alerts to the concerned organizations through WhatsApp and messaging services. Details of location and intensity of rainfall and the occurrence of floods were communicated through focused chat groups to relevant bureaucratic authorities for disaster preparedness and evacuation, if necessary. The system is currently in place and has been employed by various governmental bodies.

The system is also equipped to alert a network of trained disaster-relief workforce and the relevant authorities on the inundation and other damages (blockage of roads/electrical transmissions, etc.), through focused messaging/WhatsApp groups. This information helps in quick addressal of these issues with minimal inconvenience to the citizens.

\section{Bengaluru Megha Sandesha app}

To directly disseminate rainfall and flood forecast information along with the location-specific near-real time weather information to the citizens of Bengaluru, a mobile application, 'Bengaluru Megha Sandesha' has been developed by KSNDMC as a product of the UFM project. The in-built features of the application and the information provided by it, on an experimental basis, are a first of its kind in the country. The information is based on real-time data from $100 \mathrm{ARGs}$ (Figure 4) and 12 AWSs installed by KSNDMC across Bengaluru. Rainfall forecast is based on location-specific outputs from the WRF model of SAC. The data include rainfall, surface temperature, relative humidity, cloudiness, wind speed and wind direction. The urban flood model outcomes serve as an input to the flood inundation section and flood forecast section of the app. The flood-warning system is designed to display the occurrence of floods, based on the region-wise flood-vulnerable zones identified and their corresponding threshold rainfall that can initiate the flood scenario. The WLS located at various sensitive SWDs aid in the in situ verification of floods. Training has been conducted for relevant technocrats from various zones of Bengaluru to utilize the data from the application for flood scenarios. The application enables users to look for safer alternative routes based on high-rainfall regions en-route. This is linked to Google Maps for easy navigation. Figures 7 and 8 show a flow chart with various components of the Bengaluru Megha Sandesha flood application and the interfaces for various sections respectively. The application is available for free downloading on Android platforms.

\section{Varunamitra web portal}

Varunamitra (www.varunamitra.karnataka.gov.in) is a dedicated, dynamic web portal for weather information in the BBMP area. It includes details on the zone-wise static flood vulnerable areas, daily forecasts for rainfall, floods, etc. and real-time details of rainfall and weather 


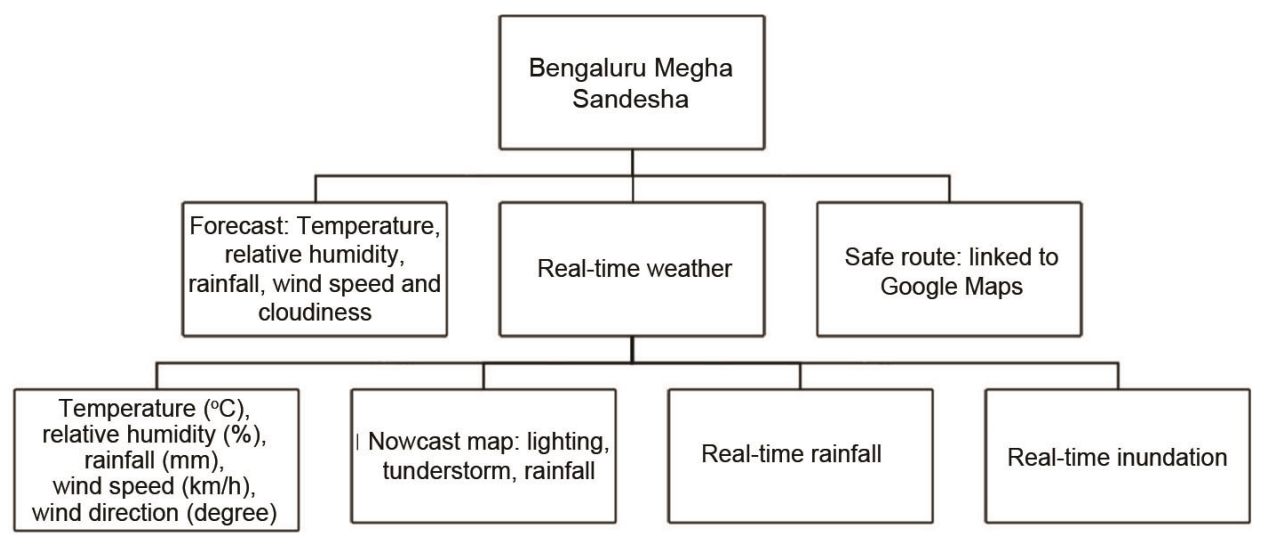

Figure 7. Components of Bengaluru Megha Sandesha flood application.

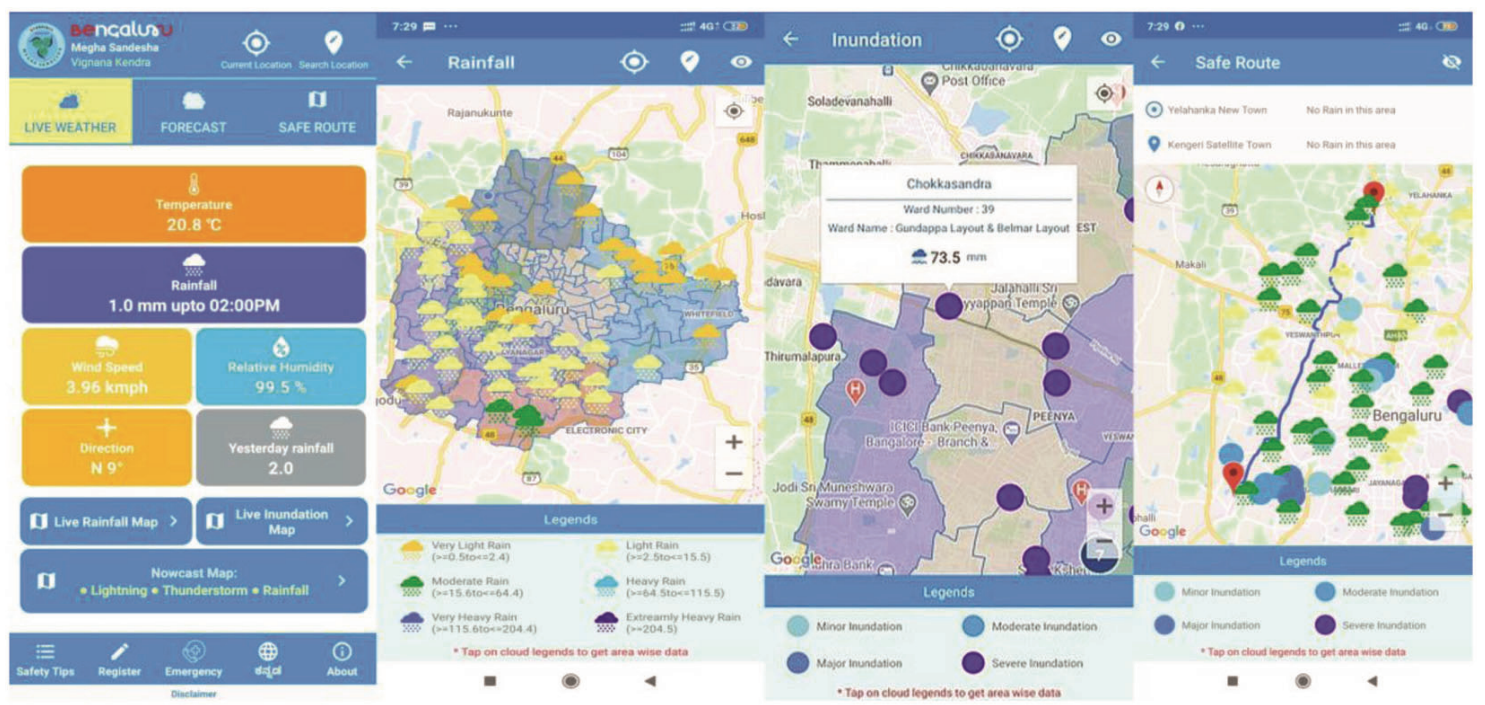

Figure 8. Bengaluru Megha Sandesha application dashboard and the interface showcasing near real-time rainfall and flood inundation, and the safe route for navigation.

information from the network of the ARG and AWS. Similar to the Bengaluru Megha Sandesha application, the forecasts are obtained from the WRF model of SAC. Figure 9 shows the real-time rainfall and flood dashboards.

\section{Innovative technologies for flood mitigation and management}

The urban flood model is also being extended to assess the possibility of reuse of flood water through innovative technologies, such as the use of low impact developments (LIDs). A few LID options include use of porous pavement technology and porous bed channels for groundwater recharge, and rainwater harvesting. These are included in the advanced version of the model, being designed to assess its impact in mitigating floods and considering floods as resources and not calamities.

\section{Documentation and packaging of flood management system}

The project components, data, flood model and mitigation and management solutions are being thoroughly documented and packaged. The packaging aims at providing streamlined solution with an efficient design for an integrated urban flood management practice. At present, it is a pilot project for integrated urban flood management solution in India.

The model is being constantly improved incorporating changes in land-use patterns (e.g. encroachment of lakes affecting the inter-lake connectivity, reduction in pervious area, etc.) and fine-resolution DEM data available from NRSC. Procurement and assimilation of very fineresolution LiDAR terrain data of up to $20 \mathrm{~cm}$ resolution is also in progress, and will be integrated in the subsequent version of the model. Laboratory experimentation 

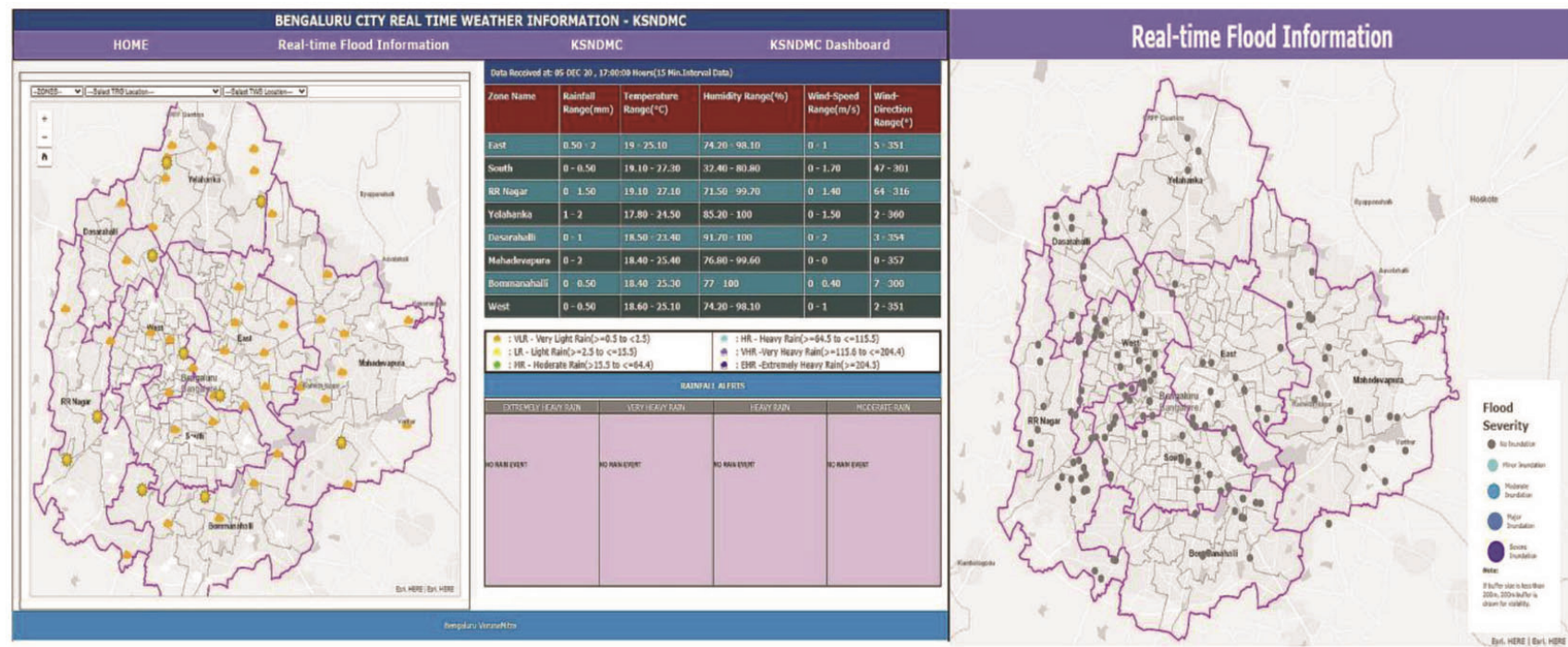

Figure 9. Real-time rainfall and flood information dashboard in the Varunamitra web portal.

(a)
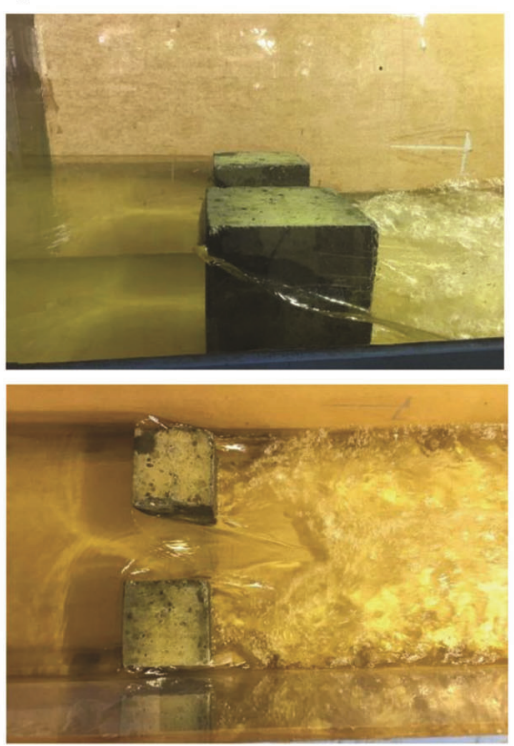

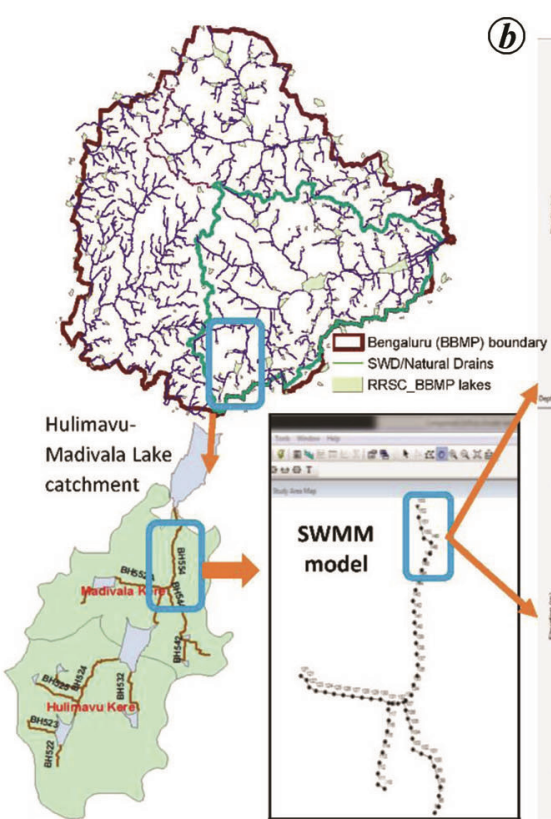

(b)
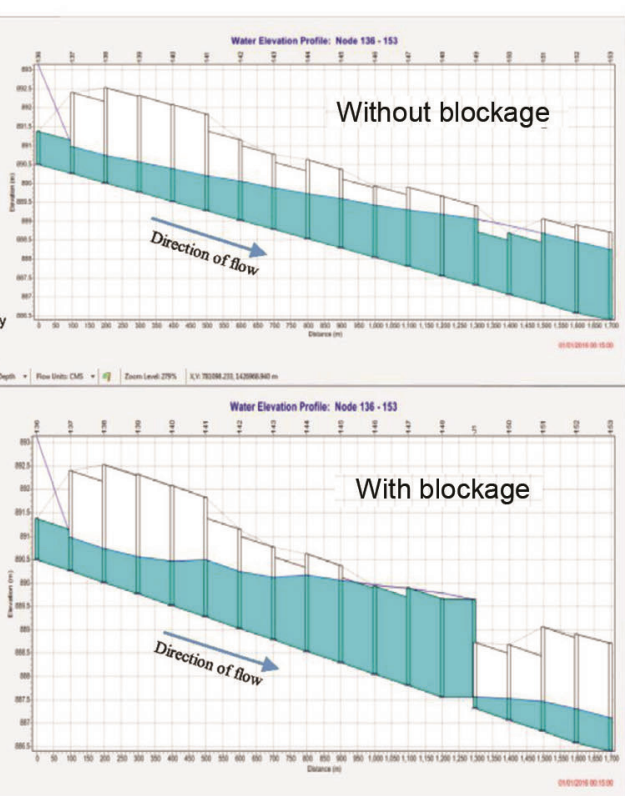

Figure 10. Channel blockage study of Hulimavu sub-basin in Bengaluru. $\boldsymbol{a}$, Laboratory set-up of field channel replica for flow with blockage. $\boldsymbol{b}$, SWMM modelling for simulated flood. Depth of flow increases upstream of the blockage and reduces downstream.

and SWMM modelling of blockages in the drainage system due to solid waste, service lines and other obstructions have been carried out as a case study on a channel in the Hulimavu sub-basin (Figure 10). Based on this case study, modelling of the floods with channel blockages for the whole Bengaluru city is under progress. The WRF forecast model at a spatial resolution of $1 \mathrm{sq} . \mathrm{km}$ is being developed for better forecasts. Experimentation and demonstration of LID applications on the ground, and also their quantification through modelling are being carried out as a part of this project.

\section{Integrated urban flood modelling at ICWaR}

The Interdisciplinary Centre for Water Research (ICWaR), IISc and KSNDMC, have collaborated on a project entitled 'Urban Flood Model for Bangalore City' to mitigate and manage flood events in urban areas of Bengaluru city. The project duration is three years (2018-2021) and is funded by the Department of Science and Technology (DST), Ministry of Science and Technology, Government of India (GoI) under demand driven convergent water solutions in mission mode. Details of the project 
are available at https://sites.google.com/site/urbanfloodmodelbangalore.

A number of projects are in progress at ICWaR, to address the problem of urban floods. A project on urban modelling and development of multi-sectorial simulation lab and science-based decision support framework to address urban environmental issues is in progress under the National Supercomputing Mission funded by DST. The Urban Climate Downscaling Portal (http://ucdp.icwar. iisc.ac.in/) has been developed by ICWaR, in collaboration with UNESCO to provide a platform with information pertaining to scientific assessments on climate change and downscaling techniques, specifically for urban areas, with the target audience as students, researchers, policy makers and practitioners worldwide.

1. Ramachandra, T. V. and Mujumdar, P. P., Urban floods: case study of Bangalore. J. Disaster Dev., 2009, 3(2), 1-99.

2. Hebbar, R. et al., Spatio-Temporal Analysis of Lakes of Bengaluru (S-TALAB), 2018.

3. Ramachandra, T. V., Vinay, S. and Bharath H. Aithal, Frequent floods in Bangalore: causes and remedial measures, ENVIS Technical Report 123, Environmental Information System, CES, Indian Institute of Science, Bengaluru, 2017.

4. Rajulapati, C. R., Gupta, H. and Mujumdar, P. P., Diurnal variability of hydrological variables in urban areas. Urban Climate, 2020, 33 100669 .
5. Rupa, C. and Mujumdar, P. P., Quantification of uncertainty in spatial return levels of urban precipitation extremes. J. Hydrol. Eng., 2018, 23(1), 04017053.

6. Huber, W. C. (n.d.), Storm Water Management Model (SWMM) bibliography. Athens, Ga.: Environmental Research Laboratory, Office of Research and Development, US Environmental Protection Agency, 1985.

ACKNOWLEDGEMENTS. The work is funded through the following projects: 'Urban Flood Model for Bengaluru City', sponsored by the Department of Science and Technology, Government of India (GoI) (project no. DST/TM/WTI/DD/2k17/62(G)2), and 'Advanced Research in Hydrology and Knowledge Dissemination', sponsored by the Ministry of Earth Science, GoI (Project No. MoES/PAMC/H\&C/41/2013PC-II). We thank KSNDMC and SAC, Ahmedabad for making available the data used in this study. The authors also thank CSTEP, Spatika Information Technologies, Geokno, BBMP, BDA and BWSSB for their role in the execution of this project. We thank the Chairman, Advisory Committee for the UFM project, Shri S. V. Ranganath (Former Chief Secretary, Government of Karnataka) and members of the Advisory Committee; Dr R. K. Dave, Dr Veena Srinivasan, Prof. B. S. Murty and Shri S. Vishwanath for their valuable suggestions. We also thank Dr Chandra Rupa, Mr Kanneganti Bhargav Kumar, Mr T. Suresh Kumar, Ms Sridevi Priya and Ms Srivani, Ms. Lubna for their role in the UFM project.

Received 11 November 2020; revised accepted 5 January 2021

doi: $10.18520 / \mathrm{cs} / \mathrm{v} 120 / \mathrm{i} 9 / 1441-1448$ 